\title{
Erratum to: The subjective well-being of individuals diagnosed with comorbid intellectual disability and attention deficit hyperactivity disorders
}

\author{
Oren Yurkevitch $^{1,2} \cdot$ Sagi Berslav $^{1} \cdot$ Tal Araten-Bergman $^{3}$
}

Published online: 19 June 2015

(C) Springer International Publishing Switzerland 2015

\section{Erratum to: Qual Life Res}

DOI 10.1007/s11136-015-0936-4

In the original publication of the article, the corresponding author has missed to cite Dr. Oren Yurkevitch and Ms. Sagi Berslav in the author group. The correct author group is given in this erratum.

The online version of the original article can be found under doi:10.1007/s11136-015-0936-4.

Tal Araten-Bergman

talaraten@gmail.com

Oren Yurkevitch

Oren@krc.org.il; Orenyur@gmail.com

1 School of Social Work, University of Haifa, Mount Carmel, 31905 Haifa, Israel

2 Rehabilitation Services, Kibbutzim Counseling and Rehabilitation Center, Herzliya, Israel

3 University of Haifa, Haifa, Israel 